\title{
DeCOLONIALIDADE, LUGAR DE FALA E VOZ-PRÁXIS ESTÉTICO-LITERÁRIA: REFLEXÕES DESDE A LITERATURA INDÍGENA BRASILEIRA
}

DECOLONIALITY, STANDPOINT OF SPEAK AND AESTHETICAL-LITERARY VOICE PRAXIS: REFLECTIONS FROM THE PERSPECTIVE OF INDIGENOUS BRAZILIAN LITERATURE

Leno Francisco Danner ${ }^{1}$

ORCID 0000-0002-2332-3182

Julie Dorrico ${ }^{2}$

ORCID 0000-0002-5428-2432

\section{Fernando Danner ${ }^{1}$}

ORCID 0000-0002-4541-1204

${ }^{1}$ Universidade Federal de Rondônia

Porto Velho, RO, Brasil

${ }^{2}$ Pontifícia Universidade Católica do Rio Grande do Sul

Porto Alegre, RS, Brasil

\section{Resumo}

Argumentaremos, por meio da análise da literatura produzida por intelectuais indígenas brasileiros/as hodiernos/as, acerca da centralidade do lugar de fala das minorias em termos de crítica, reconhecimento e resistência. Enfatizaremos a imbricação e o sustento entre epistemologia e política que convergem e aparecem diretamente no sujeitogrupo menor. Sua singularidade antropológica e sua condição de marginalização, exclusão e violência, uma vez publicizadas política e culturalmente, implicam na desnaturalização e na politização da sociedade, pluralizando histórias, experiências, sujeitos, práticas e valores. Assim, no sujeito-grupo de minorias, converge o próprio processo histórico-político de formação da sociedade, em suas potencialidades e contradiçôes. É aqui que a voz-práxis estético-literária das minorias adquire toda a sua pungência e, por meio da abertura paradigmática possibilitada pela arte, leva a uma perspectiva de descolonização da cultura e de descatequização da mente que gera crítica social acentuada e reflexividade política intensificada.

Palavras-Chave: Decolonialidade, Lugar de Fala, Minorias, Indígenas, Voz-Práxis. 


\section{Resumen}

Discutiremos, a través del análisis de la literatura producida por los intelectuales indígenas brasileños de hoy, sobre la centralidad del discurso minoritario en términos de crítica, reconocimiento y resistencia. Daremos énfasis a la imbricación y al suporte entre epistemología y política que convergen y aparecen directamente en el sujeto-grupo menor. Su singularidad antropológica y su condición de marginación, exclusión y violencia, una vez publicadas política y culturalmente, llevan a la desnaturalización y politización de la sociedad, pluralizando historias, experiencias, sujetos, prácticas y valores. Así, en el sujeto-grupo de minorías, converge el proceso histórico-político de formación de la sociedad, en sus potencialidades y contradicciones. Es aquí donde la praxis estético-literaria de las minorías adquiere toda su dramaticidad y, a través de la apertura paradigmática posible por el arte, conduce a una perspectiva de descolonización de la cultura y descatequización de la mente que genera una crítica social acentuada y una reflexividad política intensificada.

Palabras-Clave: Decolonialidad, Lugar de Habla, Minorías, Indígenas, Voz-

Práxis.

\section{Abstract}

Based on an analysis of contemporary Indigenous Brazilian literature, we will discuss the centrality of the minorities' standpoint of speech in terms of criticism, recognition and resistance. We will highlight the interconnection and interdependence between epistemology and politics that converge and appear directly in the minority subject/group. Its anthropological singularity and condition of marginalization, exclusion and violence once publicized politically and culturally, imply the denaturalization and politicization of society, pluralizing histories, experiences, subjects, practices and values. Therefore, in the minority subject/group converges the very historical-political process of formation of society, with its potentialities and contradictions. It is here that the minorities' aesthetical-literary voice praxis acquires full poignancy and, by means of the paradigmatic openness that art affords, it leads to a perspective of decolonization of culture and de-catechization of mind that generate increasing social criticism and intensified political reflexivity.

Keywords: Decoloniality, Standpoint of Speech, Minorities, Indigenous, Voice-Praxis. 
O índio que se conhece até hoje, nestes últimos 500 anos, é o índio teatralizado. Infelizmente, para a maior parte da população brasileira, o índio é um personagem, não existe de fato (WERÁ, 2017, p. 101).

Pois, se há uma certa unanimidade entre os indígenas, é de que já chega de tanta gente falando pela gente. O que a gente quer é esse espaço da fala. Já passou da hora de falar. E existe hoje uma chance real de nos apresentarmos com dignidade para a sociedade. E o próprio argumento nosso, de que não somos apresentados devidamente, tem de ser combatido com uma apresentaçáo própria, devida (ESBELL, 2018, p. 47).

No presente artigo discorremos, a partir do estudo da produção estéticoliterária de intelectuais indígenas brasileiros/as, sobre o que consideramos ser a maior inovação dos estudos coloniais, pós-coloniais ou decoloniais contemporâneos, a saber, a própria constituição de uma voz-práxis direta, carnal, política e politizante, assumida por esse mesmo indivíduo-grupo marginalizado como base da reafirmação de sua identidade antropológicocultural e, como condição para isso, de seu ativismo público-político. Nesse sentido, é o próprio indivíduo-grupo marginalizado, tornado menor em termos da colonização, produzido por ela, e em geral representado tecnicamente por um sujeito político-epistêmico extemporâneo, que constrói teoria sobre si e sobre a sociedade em que está inserido, ligando-a diretamente a uma práxis altamente política, baseada em sua singularidade antropológica e em sua condição de marginalização, de exclusão e de violência. É esta situação como singularidade e essa condição como vítima, suas experiências, histórias e motivaçóes por reconhecimento, justiça e politização, que o levam a uma luta identitária que tem na crítica social e na desnaturalização-politização da sociedade, de suas instituiçóes, de seus sujeitos e de suas histórias, o núcleo constitutivo, estruturante e dinamizador. Ao fazer isso, o sujeitogrupo produzido e justificado como menor permite a imbricação e o mútuo sustento de teoria e prática, a partir uma perspectiva autoral, autobiográfica, testemunhal e mnemônica, que transita das margens para o centro epistêmicopolítico, que confere prioridade às experiências subalternas como fundamento da crítica, do reconhecimento, da inclusão, do ativismo e da educação, para além das mediações institucionalistas, cientificistas e tecnicistas em termos de neutralidade, imparcialidade, impessoalidade e formalismo metodológicoaxiológicos.

Nosso argumento central, de que o lugar de fala das minorias políticoculturais, em termos de crítica, reconhecimento, participação, inclusão e educação, é insubstituível e irrepresentável, levando à descolonização e à descatequizaçáo da cultura, aponta para dois núcleos centrais, no texto. 
O primeiro está em que o sujeito de minorias, dada sua singularidade antropológica e sua condição de colonizado, correlaciona epistemologia e política sob a forma de ativismo dito e feito em termos de eu-nós ao mesmo tempo teorizante de si, militante sobre si, estetizante de sua condição. Ele é a própria teoria e a própria práxis em ação, vivas, pungentes, testemunhas da marginalização e da violência, porque a viveu na alma e no corpo, na pele e na mente. Segundo, seu aparecimento na esfera pública e sob a forma de sujeito político-cultural militante - e as minorias sempre são militantes leva à desnaturalização da cultura e à descatequizaçáo da mente, politizando a história nacional por meio da pluralização dos sujeitos, das histórias, das experiências, das práticas e dos valores deslegitimados e denegridos pela colonização. Desse modo, no caso dos/as intelectuais indígenas brasileiros, a promoção do ativismo estético-político traz à tona, à luz do dia, o sujeito indígena marginalizado que, por meio desse ativismo amplo possibilitado pela arte de um modo geral e pela literatura em particular, busca o diálogo com a sociedade envolvente e, aqui, a construçáo de uma nova história, de uma nova política, de uma nova cultura que têm nas experiências e na condição de violência simbólico-material por eles/as vividas, o ponto normativo básico da crítica, da reflexividade e da projeção de um novo futuro.

O sujeito epistêmico é ao mesmo tempo o sujeito militante! sobre lugar de fala, justificação normativa e ativismo político do sujeito de minorias

O século XX traz à tona e gradativamente consolida, no e pelo âmbito das ciências humanas e sociais, assim como na esfera da linguística e das artes e por elas, a categoria da diversidade, da diferença, do pluralismo, da alteridade como sua base fundante, estruturadora e definidora da constituição e da relação entre teoria e prática, do sujeito teórico e do/como sujeito político. Isso implica quatro pontos fundamentais, que definem todo o campo e todo o tipo de atuação das humanidades e de sua vinculação pública, política $\mathrm{e}$ cultural, a saber: (a) a recusa da biologia e da religiâo, das fundamentaçóes essencialistas e naturalizadas, enquanto substrato e núcleo dinamizador da justificação pública e da constituição dos saberes e das práticas socialmente vinculantes para uma sociedade em vias de modernizaçáo, para uma sociedade que, passo a passo, com alguns retrocessos, mas em geral de modo imparável, se coloca e se quer como democrática; (b) a afirmação do caráter eminentemente político-cultural do que somos como grupos humanos, como sujeitos, como sociedades localizadas no espaço e no tempo históricos, o que significa, mais uma vez, a contraposiçáo ao racismo biológico, ao fundamentalismo religioso e ao colonialismo-eurocentrismo político enquanto atitudes básicas desse pensamento-práxis contra-hegemônico; (c) a emergência de novos sujeitos 
epistemológico-políticos, as minorias político-culturais, que superam sua invisibilização, seu silenciamento e seu privatismo e consolidam uma voz-práxis enraizada na esfera pública e diretamente militante em termos normativos, em uma postura de crítica radical da cultura nacional normalizada ou do sistema-mundo produtor e reprodutor de colonialidade, de subalternização e de desigualdade; e, com isso, (d) a profunda imbricação, por essas mesmas minorias, entre epistemologia e política, entre juízo cognitivo e juízo político, entre verdade, arte e política, sob a forma de uma práxis marginal que emerge e transita na sociedade civil e que se centraliza nela, de modo que a produção do conhecimento assume, nesses novos sujeitos políticos, uma dinâmica que vai de sua condição de marginalização para sua voz e seu ativismo diretos, em muitos casos colocando em segundo termo seja a representação política parlamentar, seja a mediação técnica e cientificista da academia.

Dito de outro modo, esses grupos produzem suas próprias teorias e fundam sua própria perspectiva estético-política relativamente à sua condição e à sua causa, partindo de sua singularidade antropológica e de suas experiências de marginalização, de violência e de negação como singularidade. Note-se bem: produzem suas próprias teorias e fundam sua própria perspectiva estéticopolítica no sentido de que a sua condição - singularidade e menoridade - lhes serve como arcabouço normativo e motivação política que legitimam tanto a construção epistemológica do que são e de seu lugar teórico-prático, quanto, em consequência, esse ativismo direto que coloca a condição das minorias e o sujeito de minorias como irrepresentáveis e insubstituíveis, expressados na correlação de primeira pessoa do singular e de primeira pessoa do plural, o eu-nós epistemológico, estético e político. Não se trata, aqui, evidentemente, de negar-se todo o arcabouço político, cultural, epistemológico e institucional legado (contraditoriamente) pela modernização central às sociedades de modernização periférica, como é o caso do Brasil, mas, ainda segundo o sujeito de minorias, complementar, a partir do próprio lugar de fala e da própria condição como minoria (singularidade e menoridade), a formulação de perspectivas paradigmáticas e de práticas políticas que efetivamente tenham na pluralidade - e não mais na massificação e na unidimensionalidade - o núcleo constitutivo e dinamizador do que somos como sociedade brasileira, do que somos, de modo mais geral, como modernização. Na condição e no sujeito de minorias, portanto, a voz-práxis direta, de caráter político e politizante, profundamente carnal e vinculada à condição e à causa como minoria, determina o tipo de constituição teórica (o/a menor produzindo sua própria teoria desde sua condição como singularidade e de suas experiências de marginalização) e de aplicação prática (uma aplicação direta, o/a próprio/a menor enraizando-se publicamente e reivindicando, por meio de quem ele/a é e do que fizeram com ele/a, a reconstrução do status quo). 
$\mathrm{Na}$ condição, nas histórias e nas experiências vividas pelas e como minorias, portanto, a colonização aparece em cheio e encontra efetivamente o seu verdadeiro ponto de crítica, de enquadramento. A colonização é, ao mesmo tempo, o choque frontal entre o estrangeiro e o nativo, entre aquele que vem para tomar posse da terra, da riqueza e dos sujeitos aos quais esse mesmo estrangeiro está respaldado religiosa, normativa, moral e culturalmente a dominar, bem como, a partir daqui, um processo permanente de produção de menoridades, de legitimação da dominação do colono pelo colonizado como uma tarefa civilizatória, inclusiva e salvífica que justifica ou esconde a violência simbólico-material que é a única base para a produção dessas minorias ( $c f:$ FANON, 1968, p. 23-74; MEMMI, 1967, p. 21-76; DUSSEL, 1993, p. 17-70; MIGNOLO, 2007, p. 15-25; QUIJANO, 1992, p. 11-20). A colonização precisa, por conseguinte, para justificar-se como tarefa de humanização, de civilização e de incremento moral, fundamentar a menoridade do sujeito a ser colonizado, e isso significa: precisa deslegitimálo em sua condição e silenciá-lo e invisibilizá-lo como voz pujante, como sujeito ativo, como energia vital, diminuindo-o e reduzindo-o à animalidade, à selvageria ou à anormalidade, no mesmo momento em que o esconde dos olhos do público, em que se o despersonaliza e o despolitiza como sujeito que pode ser visto e agir à luz do dia, como um/a igual. O colonialismo, nesse sentido, é um processo político, cultural e institucional de travamento dos discursos alienígenas, de construção de menoridades moralmente decaídas, antinaturais e anormais, de banimento da vida pública, social e política dos/ as menores que ameaçam, com seu aparecimento, com sua voz e com seu corpo, a normalidade que, como consequência, é o outro lado da moeda da produçáo da menoridade, a maioridade (com todos os direitos que ela gera e promove), ou seja, a construçáo do/a menor, do/a anormal, é, ao mesmo tempo e como condição consequente e necessária para isso, a construçáo do normal, do natural, do apolítico ( $c f:$ BHABHA, 1998, p. 22-42; SPIVAK, 2010, p. 19-126; DALCASTAGNÈ, 2012, p. 49-74). E isso leva a um terceiro passo do colonialismo: se ele é marcado pela invasão civilizadora, respaldada desde fora, pela própria cultura colonizadora como seu primeiro passo, se, como segundo passo, ele leva à e exige a produção permanente da menoridade e da normalização, com o silenciamento e o apagamento do/a menor e a massificaçấo de um sujeito e de uma cultura apolíticos, esse mesmo colonialismo também consolida a representação do/a menor pelo próprio colonizador, de modo que o/a menor perde seu discurso e tem negada sua maioridade política, sendo responsabilidade exclusiva do sujeito maior que, evoluído frente àquele/a, assume uma funçáo de orientação, de guia e de formação civilizatórias, dando, como dissemos, um caráter humanizador e messiânico à colonizaçáo, ontem e hoje. $\mathrm{O} / \mathrm{a}$ menor náo pode falar e nem 
tem condiçóes de falar, para o colonizador - por isso, o sujeito maior, como tutor desse menor, deve falar por ele.

Esse arrazoado que fizemos, de todo modo, quer significar exatamente o fato de que a representação extemporânea do/a menor e sua substituição epistêmico-política pelo sujeito colonizador, que leva à invisibilização, ao silenciamento e à exclusão daquele/a por este, é o grande alvo do Movimento Indígena brasileiro e da produção estético-literária indígena que se desenvolve na esteira dele e como sua justificativa normativa, de caráter contra-hegemônico e desconstrutivo em relação ao (não)lugar, ao (não)protagonismo e à imagem (decaída, menor) do/a índio/a consolidadas pelo nosso processo de colonização e de modernização conservadora. Com efeito, tanto no Movimento Indígena brasileiro, que emerge em fins dos anos 1970, quanto na literatura indígena que é produzida com ênfase a partir da década de 1990, o falar e o agir diretamente, sob a forma de uma militância estético-política autoral e autobiográfica, definem o enfrentamento pungente e radicalizado contra as ideias de responsabilidade relativa, de paternalismo institucional e de tutela tecnocrática exercidos pelos governos militares sobre os povos indígenas, negando-lhes não apenas cidadania política, mas também e como fecho de abóboda disso a possibilidade de visibilidade pública, a efetividade de uma voz-práxis reconhecida em termos político-culturais (cf:: KRENAK, 2015, p. 86-96; MUNDURUKU, 2012, p. 17-18, p. 40; TUKANO, 2017, p. 2628; WERÁ JECUPÉ, 2002, p. 52). Nessa condição de maioridade relativa, de paternalismo institucional e de tutela tecnocrática, os indígenas seriam meros objetos do público ou do Estado, mas não sujeitos. Aqui emerge, nesse sentido, a dupla intenção seja do Movimento Indígena brasileiro, seja da literatura indígena, a partir dele dinamizada, a saber: uma voz-práxis direta, política e politizante, carnal e vinculada, do sujeito indígena por si mesmo e desde si mesmo, tendo por base sua singularidade e sua condição como menoridade; e, como consequência, a correlação de epistemologia, política e/como estética militante. Isso pode ser percebido, para começo de conversa, em uma afirmaçáo seminal feita em 1984 por Ailton Krenak - liderança política e escritor indígena - relativamente ao seu ativismo estético-político:

Meu trabalho junto à União das Naçōes Indígenas é minha vida. Porque minha vida só terá sentido na medida em que eu puder resgatar uma identidade. $\mathrm{O}$ que é isso? É afirmar a existência e o direito à existência dos índios no Brasil. É construir um Brasil onde todos possam ter seus direitos garantidos na prática, e não só no papel. [...] Essa busca de identidade, que não é só minha, mas de todos os 150 povos indígenas diferentes que vivem no Brasil, passa obrigatoriamente pela relaçáo entre o Estado e os índios. Em toda a história do Brasil, nunca houve um tratado entre o governo brasileiro e os povos indígenas. Efetivamente, o governo brasileiro nunca se dirigiu aos povos indígenas como 
naçóes, que eles são. Essa relação sempre se baseou em um ponto de vista hipócrita. E, por isso, nunca houve o menor esforço para defini-la melhor. Para o governo, para todos os governos que se sucederam na história desse país, o problema está resolvido: ignora-se o direito à existência dos índios. A própria imagem que nos é passada na escola conta-nos a seguinte história: 'Quando Cabral chegou, o Brasil era habitado por índios'. Aí fecha rápido a cortina e pronto: 'não há mais índios!'. Acontece que há (KRENAK, 2015, p. 22-23. Cf., ainda: MUNDURUKU, 2016, p. 52; MUNDURUKU, 2018, p. 25-27; WERÁ, 2017, p. 101-108; POTIGUARA, 2018, p. 115-117; GUAJAJARA, 2017, p. 19-29; TUKANO, 2017, p. 26; KOPENAWA e ALBERT, 2015, p. 64-65; ESBELL, 2018, p. 33-36; KRENAK, 2017, p. 15-16).

Note-se, na passagem, a dupla perspectiva de crítica à representação tradicional feita dos povos indígenas em termos de nossas instituiçôes, como herdeira desse processo primeiramente de colonização e, depois, de modernização conservadora: sujeitos do passado, e não do presente, não têm discurso e nem prática próprios, não conseguem assumir uma perspectiva política, cultural e epistêmica maior - não têm ciência racionalizada, não têm cultura modernizada, não têm reflexividade política (se é que isso efetivamente algum dia fez a diferença em nossa modernização conservadora, em e para nossos liberais na economia e conservadores na cultura); e, por isso, sujeitos do passado pertencem ao passado, isto é, ao profundo do mato ou do armário, afastados dos olhos dos sujeitos modernos e tendo calada sua voz frente a esses mesmos sujeitos modernos. É contra isso que, como também vimos na passagem acima, Ailton Krenak associa os passos epistêmico-políticos (a) do destino e do ativismo pessoais em nome do grupo, (b) da recuperação da própria identidade do que se é e de como se chegou a ser isso que se é, e, como caminho detonador e garantidor de tudo isso, (c) da crítica social e da visibilidade política em termos de esfera pública, pelo próprio indivíduo-grupo marginalizado, agora em uma postura autônoma e autoral relativamente à sua condição e à sua causa, relativamente ao enfrentamento das condiçóes de marginalização instauradas e reproduzidas - crítica social e ativismo epistêmico-político que ocorrem sob a forma de desnaturalização e de politização da história nacional. Há indígenas, e descobrimos que eles/as existem porque eles/as apareceram e aparecem na esfera pública, enraizandose nela e consolidando-se como sujeitos político-culturais. Nesse sentido, também podemos perceber, ainda em Ailton Krenak, mas, na verdade, em todos os intelectuais indígenas brasileiros contemporâneos, essa correlação de teoria e prática, de sujeito epistêmico e político que, imbricando eu e grupo, eu-nós, potencializa uma voz-práxis direta em que a condição identitária, sua singularidade antropológica e sua situação de marginalização, de exclusão e de violência vividas e sofridas como menoridade unem-se para constituir uma 
perspectiva altamente política, autobiográfica, testemunhal, experiencial e mnemônica da própria situação que, publicizada, revela o núcleo violento e contraditório, ainda não purgado ou resolvido, do processo de formação e de evolução de nossa sociedade. Mais uma vez, Ailton Krenak nos diz:

E o outro desconforto era me identificar como índio, porque índio é um erro de português, plagiando o Oswald, que disse que, quando o português chegou ao Brasil, estava uma baita chuva, aí ele vestiu o índio, mas, se estivesse num dia de sol, o índio teria vestido o português, e estaria todo mundo andando pelado por aí. Isso continua valendo até hoje, e eu atualizei dizendo que o índio é um equívoco do português, mas não um erro, porque o português saiu para ir para a Índia. Mas ele perdeu a pista e veio bater aqui nas terras tropicais de Pindorama, viu os transeuntes da praia e acabou carimbando de índios. Aquele carimbo errado, equívoco, ficou valendo para o resto das nossas relaçôes até hoje, e a resposta para uma pergunta tão direta e simples (sobre o sentido do ativismo indígena) poderia ser táo direta e simples quanto. Quando foi que eu atinei que eu tinha que fazer essas coisas que eu ando fazendo nos últimos 50 anos da minha vida, que é quase que repetir o mesmo mantra, dizendo para esse outro: 'Ô, cara, essa figura que você está vendo no espelho náo sou eu não, é você, esse espelhinho que você está me vendendo não sou eu, isso é um equívoco'? E saí do sentimento para a prática na pista dos meus parentes mais velhos do que eu, que estavam sendo despachados da zona rural para as periferias miseráveis do Brasil, o que acontece em qualquer canto, no Norte, no Sul, em qualquer lugar (KRENAK, 2015, p. 239. Cf. ainda: MUNDURUKU, 2016, p. 19-21).

A perspectiva anticolonial, decolonial ou pós-colonial por excelência, como podemos ver nessa passagem, em que Ailton Krenak nos explicita a sua condição e o sentido de seu ativismo, isto é, a luta em prol do grupo marginalizado e feito menor pela colonizaçáo, consiste exatamente na imbricação e na mútua dependência de teoria e prática, de epistemologia e política, que são subsumidas pelo próprio indivíduo-grupo menor. No caso das minorias político-culturais, essa imbricação e mútua dependência simplesmente aparece de modo direto por causa da sua condição como menor, pelo fato de que a minoria está exatamente na confluência de processos de violência simbólico-materiais em que modelos paradigmáticos e exemplares de sociedade, de homem, de prática e de valor, ao serem normalizados, naturalizados e despolitizados, produzem correlatamente, para sua justificação e seu sustento, a sua antítese, o/a anormal, o indivíduo moralmente decaído, o estigma, o antinatural. No caso dos povos indígenas, sua condição pré-civilizacional, sua barbárie e sua animalidade como que inatas, ou mesmo o fato de, como sugeria Pero Vaz de Caminha, serem como páginas em branco nas quais se poderia, desde a sábia mão do europeu, escrever a melhor poesia, realizar-se o paraíso 
na terra, legitimam o trabalho civilizacional da colonização, a aculturação e, quando necessário, a morte e, com isso, apagam a singularidade, a dignidade e o protagonismo desses mesmos indígenas. Por isso, seu aparecimento na esfera pública e como sujeitos político-culturais traz à tona as contradiçôes do colonialismo, de nossa modernização conservadora, desnaturalizandoas e politizando-as. No que se refere às minorias político-culturais de um modo geral e aos povos indígenas em particular, a voz-práxis estético-literária direta, que promove concomitantemente sua singularidade antropológica e sua condição como menoridade violentada, produzida enquanto estigma, contribui diretamente para essa perspectiva politica e politizante, carnal e vinculada do sujeito epistêmico-político, imbricando, portanto, epistemologia e política no e como sujeito de minorias.

Da invisibilização e do silenciamento ao protagonismo público, político e cultural: literatura indígena como descolonização da cultura e descatequização da mente

Como dissemos acima, a grande novidade e o profundo impacto epistêmico-político dos estudos coloniais, pós-coloniais ou decoloniais consiste nesse ponto que lhes é comum, isto é, de se caracterizarem e dinamizarem pelo aparecimento e enraizamento público-político das minorias político-culturais e dos sujeitos de minorias que revelam exatamente o caráter contraditório da colonização, do eurocentrismo e, com isso, desnaturalizam e politizam a cultura nacional e essa relação entre modernização central e modernização periférica. As minorias estáo na fronteira desse processo, ou seja, elas correlacionam a cultura e o sujeito colonizadores, os processos simbólico-materiais de produção das minorias e, como condição de tudo isso, os sujeitos-grupos alienígenas os quais o colonizador assume como propriedade e como massa a ser moldada e orientada pela missão civilizadora do encontro, da descoberta. Aparecendo na esfera pública e nela enraizando-se e consolidando-se como sujeitos políticoculturais, as minorias podem descontruir essa justificação naturalizada e apolítica da violência colonial, afinal a descoberta e a consequente colonizaçáo da terra e de seus povos não tiveram um aspecto civilizador, mas uma postura de violência, de negação, de estupro do/a colonizado, sua despersonalização e seu genocídio institucionalizados, cultural e normativamente respaldados. Nesse diapasão, o movimento descolonizador por excelência é e se define por esse caminho e por essa postura das minorias que rompem com o silenciamento, a invisibilização e o privatismo, aos quais foram empurradas ao longo da colonização, e assumem uma atitude pública, política e cultural de militância, de ativismo e de engajamento em torno à sua condição e à sua causa como minorias. 
Ora, esse aparecimento e esse ativismo públicos, por parte das minorias, por parte do sujeito de minorias, traz a própria condição como minoria para o núcleo do processo constitutivo-evolutivo de nossa sociedade, desnaturalizando-o e politizando-o de modo direto. E por que isso? Porque, ao aparecer, as minorias e os sujeitos de minorias não podem esconder quem são, uma vez que seu próprio corpo, suas próprias tradiçôes, suas próprias práticas visibilizam a condição de chaga, de estigma e de anormalidade que lhes foram impostas e, por isso mesmo, também publicizam e vociferam acerca de quem fez isso com eles/as, do que se fez com eles/as e de como se fez isso, desconstruindo - isto é, desnaturalizando e politizando - a história, os sujeitos, as práticas e os valores exemplares de nossa sociedade. "De fato", diz-nos o intelectual e escritor macuxi Jaider Esbell, "minha face nunca me deixou passar imperceptível” (ESBELL, 2018, p. 125. Cf., ainda: JECUPÉ WERÁ, 2002, p. 15-22). A face-corpo-tradição do sujeito de minorias foi uma das bases de sua construção como menoridade, de sua justificação como estigma; e, hoje, é o fundamento para sua - das minorias, do sujeito de minorias - reafirmação e revalorização da própria identidade negada, para o restabelecimento próprio, político, de sua dignidade. As tradiçóes culturais e as práticas de vida próprias às minorias, que antes foram a base para sua deslegitimaçáo e para sua negaçáo, hoje lhes servem como núcleo para a reconstituição do que são efetivamente como singularidade, mas também como crítica social aguda do que fizeram com eles/as em termos de colonização. Como dissemos, essa superação da invisibilização, do silenciamento e do privatismo acontece e é assumida, por parte das minorias, desde essa perspectiva de publicizar a voz, de politizar, via ativismo e engajamento, a história nacional e nossos sujeitos político-culturais exemplares por meio do lugar de fala político, esteticamente mediado, isto é, por meio da voz pública, das experiências e histórias como minorias contadas a todos/as, espalhadas aos quatro ventos via voz-práxis estético-literária. Nessa situaçáo de politização das e pelas minorias, tem-se a transformação da arte e, em especial no nosso caso, da literatura em perspectiva anticolonial de resistência, luta e reelaboração do que se é, em crítica e enquadramento da sociedade envolvente. Vejamos, acerca dessa publicização da voz, das histórias e das experiências das e pelas minorias, uma passagem do livro Metade cara, metade máscara, da indígena Eliane Potiguara:

\author{
E tu choras \\ E tu sofres pela incompreensão \\ E tu morres \\ Pelo roubo e assassinato. \\ Por que ficas parada? \\ No dia em que rastejastes \\ E no que apanhaste na cara
}


Vi a teu lado a miséria e a morte

Companheiras fiéis.

Tu que te banhaste em teu próprio sangue

Não tem coragem de exclamar

Ou tem medo de ser errante?

Tu que sentiste

O racismo na carne

O desprezo dos olhares

A inveja de serem

Pelo menos um minuto

O que hoje és: HONESTA!

Tu calas, mas vejo teu sorriso

Da compreensão deste mundo

Na ruga do pé do olho

No canto da boca rota.

E penso mesmo, talvez...

Que seja, por enquanto, calar e olhar ao redor.

Porque tua mente viaja

E enxerga...

E és nobre por calar-te nesta hora

És humilde e guerreira.

Mas sei que tens uma cachoeira de lágrimas

Dentro do peito

E uma enorme garra na VOZ

Pra gritar esse massacre SEM PAZ

Mas luta, mesmo que não possas falar

Por ora, minha TERRA

Porque ainda estás presa

Nas garras da tua própria história

(POTIGUARA, 2018, p. 81-82. Cf. ainda: ESBELL, 2013, p. 63, p. 73; JEKUPÉ, 2002, p. 07 e p. 13)

Note-se, nessa passagem, que a experiência fundamental das minorias e, nesse caso, dos povos indígenas, quando inserida no contexto maior da constituição, do desenvolvimento e da evolução de nossa sociedade, consiste na violência, na exclusão e na marginalização, quando não no assassinato sistemático puro e simples dos/as seus/suas. Nesse sentido, à experiência da violência original e por meio das histórias em que essa mesma violência original foi dinamizada ao longo do tempo, temos a emergência de novas perspectivas relativamente ao que fomos, ao que somos e ao que precisamos fazer enquanto sociedade brasileira de um modo mais geral. Esse grito público do indivíduo feito menor e esse ativismo político das minorias, por conseguinte, expressam, por um lado, a permanência dessa atitude de violência original aplicada em termos de colonização como justificação para o embranquecimento e a 
modernização da cultura e de nossos povos fundadores (os/as indígenas e os/ as negros/as, portanto, como medidos, enquadrados e avaliados pela métrica do embranquecimento como ideal moral, humanizador e civilizacional); e, segundo, leva ao enraizamento público e ao ativismo político-cultural das e pelas minorias como a única alternativa possivel de resistência, de sobrevivência. Para sobreviverem, portanto, as minorias tiveram e têm permanentemente de tornar-se políticas, sujeitos políticos; já não basta o esconder-se dentro do mato e/ou do armário, o silenciamento, a invisibilização e o privatismo diante da força bruta, do fundamentalismo religioso e do preconceito racial. É preciso politizar-se, politizar o corpo, a cultura, a condição, as histórias, as formas de vida, as práticas e os valores. Ora, essa é uma das funçóes centrais e um dos papéis mais básicos - a politização de si e do grupo - assumidos pelos/as intelectuais e escritores/as de minorias. Como diz o escritor indígena Daniel Munduruku:

Basicamente, hoje, a minha atuaçáo no movimento indígena se dá por intermédio da literatura. Com qual objetivo? Eu gosto de pensar que estou ajudando o Brasil a desentortar seu pensamento. Gosto de pensar que estou ajudando o Brasil a olhar para os povos indígenas sem o crivo dos estereótipos, sem a venda da ignorância, porque isso permitiria a todos nós termos uma ideia mais objetiva de nosso processo histórico, colocando os povos indígenas nos lugares onde eles escolhem [...]. Tenho dito, em função disso, que o meu trabalho consiste em arrancar da cabeça das pessoas essa palavra, um tanto maldita, no sentido do mau-dizer, que é a palavra índio, que carrega consigo todos os estereótipos e todos os preconceitos possíveis e imagináveis. Tem sido basicamente minha luta, minha jornada, de fazer com que as pessoas não nos chamem por esse apelido, mas por nossos nomes, pelo que somos de fato, e não pelo que elas acham que nós somos (MUNDURUKU, 2018, p. 109. Cf., ainda: MUNDURUKU, 2016, p. 172-192; WERÁ, 2017, p. 29-30; TUKANO, 2017, p. 27; JEKUPÉ, 2009, p. 11-13).

Por isso, conforme Jaider Esbell, é hora de as minorias falarem, é tempo de os povos indígenas falarem, publicizarem sua perspectiva étnica, cultural e antropológica, bem como suas experiências de marginalização, de exclusão e de violência vividas e sofridas. Por isso, para os povos indígenas, para as minorias culturais, para os grupos subalternos à modernização ocidental, profundamente determinada e orientada pelo colonialismo, ontem e hoje, a experiência fundamental de modernização, que é a violência, a exclusão e o silenciamento, deve ser enfrentada exatamente pela visibilizaçáo, pela enunciação autoral da própria voz, pela publicização das experiências e das histórias próprias, pela politização da própria condição, bem como por um ativismo direto e pungente que, ao superar a representação institucionalista 
e epistêmica, de caráter lógico-técnico, confere centralidade ao próprio indivíduo-grupo menor e, com isso, lhe possibilita desconstruir essa ideia de menoridade que não apenas justifica sua anulação, sua despersonalização e seu silenciamento, mas também e concomitantemente confere legitimidade à permanência da colonização. A voz-práxis das minorias, de caráter político e politizante, carnal e vinculada, portanto, é o fundamento da descolonização da cultura e da descatequização da mente, isto é, do enquadramento, da crítica e da correção da modernização ocidental de um modo geral e da modernização conservadora brasileira em particular.

Como é viver na modernidade? Como manter-se presente se não dissermos quem somos? Se não o somos como tais, nada seremos e vagaremos indigentes nas vias das grandes incógnitas. É nesse mostrar-se, nesse dizer coletivo que reside toda a força da arte entre nós, índios, e não na ideia central de um ponto fixo para a pura abstraçáo do outro externo (ESBELL, 2018, p. 85. Cf. ainda: POTIGUARA, 2018, p. 20-30; KOPENAWA e ALBERT, 2015, p. 511; KRENAK, 2019, p. 09-33).

\section{Considerações finais}

Uma democracia não pode sobreviver silenciando, negando ou deslegitimando suas fraturas, suas contradições, suas irracionalidades, como se elas não existissem, como se fossem um produto do passado sem qualquer resquício ou respingo no presente. É preciso reinterpretar criticamente o passado e pluralizar os sujeitos e as histórias sobre o presente. No mesmo diapasão, a crítica da modernidade, muito em voga hoje, não pode centrar-se apenas no discurso teórico-político euronorcêntrico sobre a própria capacidade de a modernidade corrigir-se internamente por si mesma e desde si mesma. É preciso que as vítimas da colonização falem. Suas histórias, suas experiências, suas práticas e seus valores são fundamentais na democracia. Sua voz-práxis é insubstituível no processo de maturação de nossa história nacional, inclusive para a correçáo da modernidade de um modo mais geral. Sem o lugar de fala das minorias aproximamo-nos perigosamente do fascismo. Como nos disse Jaider Esbell no texto, é hora de os povos indígenas falarem sobre suas experiências de modernidade, de brasilidade, ou seja, sobre suas experiências de colonização, porque a verdadeira crítica do colonialismo, de nossa modernização conservadora se faz a partir dos, com os e pelos grupos subalternos por ela produzidos, se realiza com o protagonismo da voz-práxis das minorias. 
BHABHA, Homi K. O Local da Cultura. Belo Horizonte: Editora da UFMG, 1998.

DALCASTAGNÈ, Regina. Literatura brasileira contemporânea: um território contestado. Vinhedo: Editora Horizonte, 2012.

DUSSEL, Enrique. 1492, o encobrimento do outro: a origem do mito da modernidade. Petrópolis: Vozes, 1993.

ESBELL, Jaider. Jaider Esbell. Organização de Sérgio Cohn e Idjahure Kadiwel. Rio de Janeiro: Azougue Editorial, 2018 (Coleção Tembetá).

ESBELL, Jaider. Tardes de agosto, manhäs de setembro, noites de outubro. Boa Vista: Edição do Autor, 2013.

FANON, Frantz. Os condenados da terra. Rio de Janeiro: Civilização Brasileira, 1968.

GUAJAJARA, Sônia. Sônia Guajajara. Organização de Sérgio Cohn e Idjahure Kadiwel. Rio de Janeiro: Azougue Editorial, 2018 (Coleção Tembetá).

JEKUPÉ, Olívio. Literatura escrita pelos povos da floresta. São Paulo: Scortecci, 2009.

JEKUPÉ, Olívio. Xerekó arandu: a morte de Kretã. São Paulo: Peirópolis, 2002.

KOPENAWA, Davi; ALBERT, Bruce. A queda do céu: palavras de um xamã yanomami. São Paulo: Companhia das Letras, 2015.

KRENAK, Ailton. Encontros. Organização de Sérgio Cohn. Rio de Janeiro: Azougue Editorial, 2015.

KRENAK, Ailton. Ailton Krenak. Organização de Sérgio Cohn e Idjahure Kadiwel. Rio de Janeiro: Azougue Editorial, 2017 (Coleção Tembetá).

KRENAK, Ailton. Ideias para adiar o fim do mundo. São Paulo: Companhia das Letras, 2019.

MEMMI, Albert. Retrato do colonizado precedido pelo retrato do colonizador. Rio de Janeiro: Paz e Terra, 1967.

MIGNOLO, Walter. La idea de América Latina: la herida colonial y la opción decolonial. Barcelona: Editorial Gedisa, 2007.

MUNDURUKU, Daniel. Memórias de indio: uma quase autobiografia. Porto Alegre: EDELBRA, 2016.

MUNDURUKU, Daniel. Daniel Munduruku. Organização de Sérgio Cohn e Idjahure Kadiwel. Rio de Janeiro: Azougue Editorial, 2018 (Coleçâo Tembetá). 
MUNDURUKU, Daniel. O caráter educativo do movimento indígena brasileiro (1970-1980). São Paulo: Paulinas, 2012.

POTIGUARA, Eliane. Metade cara, metade máscara. Lorena: DM Projetos Especiais, 2018.

QUIJANO, Aníbal. Colonialidad y modernidad/racionalidade. Perú Indígena, vol. 13, no. 29, p. 11-20, 1992.

SPIVAK, Gayatri Chakravorty. Pode o subalterno falar? Belo Horizonte: Editora da UFMG, 2014.

TUKANO, Álvaro. Álvaro Tukano. Organização de Sérgio Cohn e Idjahure Kadiwel. Rio de Janeiro: Azougue Editorial, 2017 (Coleção Tembetá).

WERÁ, Kaká. Kaká Werá. Organização de Sérgio Cohn e Idjahure Kadiwel. Rio de Janeiro: Azougue Editorial, 2017 (Coleção Tembetá).

WERÁ JECUPÉ, Kaká. Oré Awé Roiru'a Ma: todas as vezes que dissemos adeus. São Paulo: TRIOM, 2002.

Leno Danner. Doutor em Filosofia (PUCRS). Professor de Ética e Filosofia Política no Departamento de Filosofia e no Programa de Pós-Graduação em Filosofia da Universidade Federal de Rondônia (UNIR). Suas áreas de especialização são teorias da modernidade, pensamento social brasileiro, teorias políticas contemporâneas, pensamento indígena brasileiro, descolonização africana. Interessa-se, ainda, por filosofia latino-americana, teoria feminista e teoria queer.

E-mail: leno_danner@yahoo.com.br

Julie Dorrico. Doutoranda em Teoria da Literatura pelo Programa de Pós-Graduação em Letras da Pontifícia Universidade Católica do Rio Grande do Sul (PUCRS). Suas áreas de pesquisa são literatura e autobiografia indígenas.

E-mail: juliedorrico@gmail.com

Fernando Danner. Doutor em Filosofia pela Pontifícia Universidade Católica do Rio Grande do Sul (PUCRS). Professor de Filosofia Política no Departamento de Filosofia e no Programa de Pós-Graduação em Filosofia da Universidade Federal de Rondônia (UNIR). Suas áreas de estudo incluem filosofia política contemporânea, filosofia francesa contemporânea, filosofia latino-americana, filosofia brasileira e pensamento indígena brasileiro.

E-mail: fernando.danner@gmail.com 